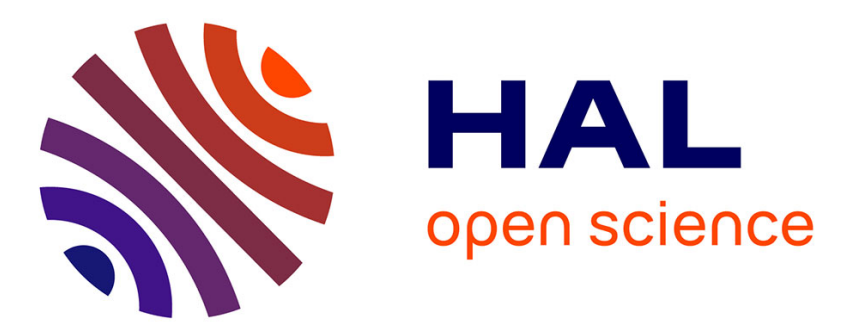

\title{
Physical model for damage prediction in structures due to underground excavations
}

\author{
Luyen Nghiem, Marwan Al Heib, Fabrice Emeriault
}

\section{To cite this version:}

Luyen Nghiem, Marwan Al Heib, Fabrice Emeriault. Physical model for damage prediction in structures due to underground excavations. International conference on geotechnical engineering

(Geoshanghai 2014), May 2014, Shanghai, China. pp.155-164. ineris-01863823

HAL Id: ineris-01863823

https://hal-ineris.archives-ouvertes.fr/ineris-01863823

Submitted on 29 Aug 2018

HAL is a multi-disciplinary open access archive for the deposit and dissemination of scientific research documents, whether they are published or not. The documents may come from teaching and research institutions in France or abroad, or from public or private research centers.
L'archive ouverte pluridisciplinaire HAL, est destinée au dépôt et à la diffusion de documents scientifiques de niveau recherche, publiés ou non, émanant des établissements d'enseignement et de recherche français ou étrangers, des laboratoires publics ou privés. 


\title{
Physical model for damage prediction in structures due to underground excavations
}

\author{
H.L. NGHIEM ${ }^{1,2}$, M. AL HEIB ${ }^{2}$, F. EMERIAULT ${ }^{1}$ \\ ${ }^{1}$ Grenoble-INP, UJF-Grenoble 1, CNRS UMR 5521, 3SR Lab, Grenoble F-38041, \\ France; huuluyen.nghiem@3sr-grenoble.fr, Huu-Luyen.NGHIEM@ineris.fr \\ ${ }^{2}$ INERIS -Parc technologique Alata-60550 Verneuil en Halatte-France
}

\begin{abstract}
Assessing the potential of building damage is a critical issue for existing and new building projects. Simple analytical approaches are still up to now mainly considered to assess the vulnerability of structures. This paper presents a new approach based on a small-scale physical model (1/40 scale factor on the dimensions) under normal gravity. It has been designed for developing and validating experimentally new methods of prediction of damages to masonry structures induced by subsidence (generally resulting from underground excavations of tunnels and mines). The analogical soil is homogenous sand allowing the realization of different simulations. The masonry structure consists of walls built with wood pieces without cohesion (mortar) resting on an elastic foundation. The vertical displacements are applied through the use of an electromechanical jack. The technique of Digital Image Correlation (DIC) is used to measure accurately the displacements and the deformations of the structure. The identification of the damage level is based on the crack width resulting from different vertical displacements. A specific algorithm has been developed to quantify the strain of joints. The total length of opened cracks appears to be a more relevant indicator of damage than the maximum width of cracks. The damage evolution with the vertical displacement can be divided into an initial linear part and a subsequent non-linear part. Guidelines are suggested for the assessment of the masonry damages due to underground excavations.
\end{abstract}

\section{INTRODUCTION}

The movements at the ground surface associated with the collapse of underground structures (tunnels or mines) can increase the vulnerability of existing structures (buildings or infrastructures). Damage is induced by several mechanisms: horizontal deformation, slope and curvature of ground surface. The horizontal deformation is responsible for an increase of uniform compression or tension in the structure, the slope causes an additional out-of-plan instability and 
the curvature either in hogging or sagging induces in particular an increase of tension in respectively the upper or lower part of the structure.

Currently, three families of methods are available for the damage assessment: methods of score points (e.g. polish method), methods based on equivalent beams and functional methods. Methods of equivalent beams are the most popular because of their simplicity. The evaluation of the damage level is based on some indicators such as the average angular distortion (Boscardin and Cording 1989), the ratio of deflection (Burland 1997), the relative rigidity (Potts and Addenbrooke 1997 ; Deck and Singh 2012) and the total distortion of structure (Boone 2002). These methods are useful to assess the impact of ground movements on the existing structure at a preliminary design phase. However, they are highly idealized and often overestimate or underestimate the true potential of structural damage. The functional methods (e.g. Saeidi et al. 2009), based on the statistical analysis of actual cases, can evaluate the damage of groups or categories of buildings in a subsidence area (according to their sizes, geometries, types of structures or materials). The main disadvantage of these methods is that they do not give information on the mechanism of damage in the structure.

In the present research, we develop a new small-scale physical model in order to study the response of masonry structures to ground movements caused by subsidence. The whole test facility was designed to investigate the influence of position of the structure with respect to the ground movement profile (Hor et al. 2011) and the protection methods such as periphery trench (Caudron et al. 2012). In this paper a new methodology is proposed for characterizing the damage and its evolution based on the displacement fields obtained by Digital Image Correlation (DIC).

\section{SMALL SCALE MODEL FOR SOIL-MASONRY INTERACTION}

The subsidence without the structure is usually characterized by main parameters such as amplitude of subsidence Am, influence angle $\gamma$, maximum strain angle $\theta$ (Fig. 1). In case of the presence of the structure on surface, some additional parameters are defined such as deformation $\varepsilon$, average slope $\alpha$, deflection $\Delta$ and radius curvature $\mathrm{R}$.

In the last decade, INERIS has lead research programs on the interaction between soil and structures, specifically for underground cavities, using numerical and 1g physical models (Deck 2002; Abbass Fayad 2004; Caudron 2007;Hor 2012). In particular, a large small-scale physical model has been designed to reproduce the phenomena and to assess qualitatively, and to a certain extend quantitatively, the soil-structure interactions and the vulnerability of masonry structures (typically individual houses). The model is equipped with high resolution digital cameras that enable through the use of Digital Image Correlation (DIC) to determine accurately the displacements fields. The Fig. 1a presents the problem with the house of dimensions $10 \times 10 \mathrm{~m}^{2}$ and the depth of cavity is $12 \mathrm{~m}$. According to the theory of dimensional analysis, the similitude laws must be respected as proposed by Dehousse and Arnould 1971 for the elastic material and 
Bazant 2005 for the fragile material. However, the scaling laws between prototype and model are generally difficult to fulfill, in particular in the case of $1 \mathrm{~g}$ tests because of limitations in the choice of materials and equipment available. In the present model, the priority is given to the similitude of geometry (length, area, volume) as discussed in Hor et al. 2011.

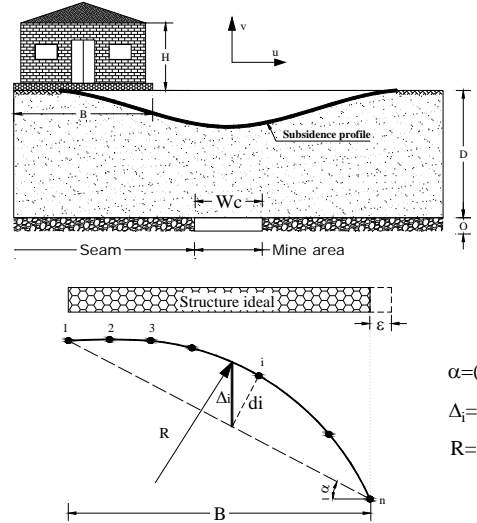

(a)
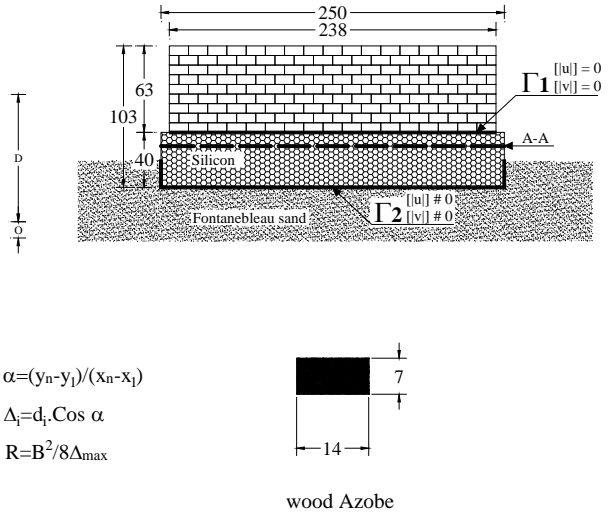

wood Azobe

(b)

FIG. 1. Description of the problem: (a) Building on subsidence area (O: open layer, D: depth, Wc: critical width, B: width of building, H: height of building $\alpha$ : average slope, $\Delta$ : deflection, R: radius of curvature); (b) Physical model of an individual house with $1 / 40$ scale factor $\left(\Gamma_{1}\right.$ : wall - foundation interface, $\Gamma_{2}$ : foundation - soil interface).

Table 1. Characteristics of Fontainebleau NE 34 sand.

\begin{tabular}{|c|c|c|c|c|c|}
\hline State & $\begin{array}{c}\text { Unit weight } \\
\left(\mathrm{kN} / \mathrm{m}^{3}\right)\end{array}$ & Dr (\%) & $\begin{array}{c}\text { Young } \\
\text { modulus E } \\
(\mathrm{MPa})\end{array}$ & $\begin{array}{c}\text { Peak Friction } \\
\text { angle }\left(^{\circ}\right)\end{array}$ & $\begin{array}{c}\text { Residual } \\
\text { Friction angle } \\
\left({ }^{\circ}\right)\end{array}$ \\
\hline Medium & 15.42 & 44 & - & 30 to 36 & 24 to 33 \\
\hline
\end{tabular}

Table 2. Characteristics of the Azobe wood used for the masonry structure.

\begin{tabular}{|c|l|c|c|c|}
\hline \multicolumn{2}{|c|}{ Parameter } & Prototype & Ideal model & Wood Azobe \\
\hline \multirow{4}{*}{ BLOCKS } & Dimension $(\mathrm{mm})$ & $200 \times 250 \times 500$ & $5 \times 6.25 \times 12.5$ & $7 \times 7 \times 14$ \\
\cline { 2 - 5 } & Unit weight $\left(\mathrm{kN} / \mathrm{m}^{3}\right)$ & 8.9 & 8.9 & 10.3 \\
\cline { 2 - 5 } & Young modulus E $(\mathrm{GPa})$ & 10000 & 10000 & $16000-19000$ \\
\cline { 2 - 5 } & Friction angle $\left({ }^{\circ}\right)$ & $20-35$ & $20-35$ & $30 \pm 9$ \\
\hline MORTAR & Cohesion $(\mathrm{MPa})$ & $0.5-1.2$ & $0.0125-0,03$ & No used \\
\hline
\end{tabular}

A model soil has been used for the validation of the ability of the physical model to reproduce the phenomena observed at large scale. Fontainebleau sand (essentially silica with $\mathrm{SiO} 2>98 \%$ ) is well-known to researchers in physical geotechnical modelling (Garnier 2002). This sand is very smooth and for our purposes category NE 34 sand was chosen (Table 1). The considered grade of 
Fontainebleau sand $\left(\mathrm{D}_{50}=200 \mu \mathrm{m}\right)$ has on the one side less negative effects, due to scale ratio of the physical model, on the transfer of movements from soil to structure than another type of sand but on the other side, allows the use of DIC with a satisfying accuracy of the displacements determination (5/100 of a pixel, i.e. $0,02 \mathrm{~mm}$ at model scale).

The model of structure is made of a silicone raft foundation and of walls build with wood blocks (Fig. 1b and Table 2). The comparison of difference models (polycarbonate slab, silicon slab, sugar blocks, wood blocks) has been presented in a recent paper ( Al Heib et al. 2013). For the sake of simplicity, the first series of tests consider a masonry structure without cohesion (mortar) between the blocks. This assumption also takes into account the fact that scaling laws will lead to very low values of the cohesion between blocks (cf. table 2) that are not easy to reproduce with the required level of homogeneity throughout the structure.

The test procedure can be summarized in three main steps: 1) The tank is first filled with a homogeneous layer of Fontainebleau sand (a specific procedure has been defined in order to obtain a uniform density over the 0,30 thick layer). 2) The subsidence is reproduced using the mechanical-electrical jack with a sufficiently low speed $(0.15 \mathrm{~mm} / \mathrm{s})$ to create the vertical displacement of a 250x250 mm plate at the bottom of the tank. The displacements of the ground surface and of the structure are captured by four rapid high resolution cameras (using the VIC-Snap software). 3) The images are analysed with the software VIC-3D in order to determine the displacement fields in the 3 directions and calculate the corresponding strain fields.

Table 3. Damage classification system proposed by Burland 1997 and Boscardin and Cording 1989.

\begin{tabular}{|l|l|l|l|}
\hline Category & $\begin{array}{l}\text { Damage } \\
\text { class }\end{array}$ & Crack width (mm) & $\begin{array}{l}\text { Limiting tensile strain } \\
\mathbf{( \% )}\end{array}$ \\
\hline Aesthetic damage & Negligible & $0-0.1 \mathrm{~mm}$ & $0-0.05$ \\
\cline { 2 - 4 } & Very slight & $0.1-1 \mathrm{~mm}$ & $0.05-0.075$ \\
\cline { 2 - 4 } & Slight & $1-5 \mathrm{~mm}$ & $0.075-0.15$ \\
\hline $\begin{array}{l}\text { Functional damage, } \\
\text { affecting } \\
\text { serviceability }\end{array}$ & Moderate & $\begin{array}{l}5-15 \mathrm{~mm} \text { or a number } \\
\text { of cracks }>3 \mathrm{~mm}\end{array}$ & $0.15-0.3$ \\
\cline { 2 - 4 } & Severe & $\begin{array}{l}15-25 \mathrm{~mm} \text { but also } \\
\text { depends on number of } \\
\text { cracks }\end{array}$ & $>0.3$ \\
\hline $\begin{array}{l}\text { Structural damage, } \\
\text { affecting stability }\end{array}$ & Very severe & $\begin{array}{l}>25 \text { mm, but depends } \\
\text { on numbers of cracks }\end{array}$ & $>0.3$ \\
\hline
\end{tabular}

\section{METHODOLOGY FOR DAMAGE EVALUATION}

Table 3 summarizes the definition of the categories of vulnerability with the corresponding crack width (Burland 1997) and limiting tensile strain (Boscardin and Cording 1989).The DIC analysis provides the full information for points on the surface such as coordinates and displacements. However, it is difficult to identify the exact points located on the interface between two blocks and during the process of DIC information may be lots in some local points (non- 
convergence of DIC). This explains the difficultly in quantification of joint opening width. Here, we propose a simple algorithm to overcome this difficulty. The idea of the algorithm is first to determine the differential normal displacement of the 2 sides of a part of the interface between two blocks, and then the association of the corresponding partial length of the interface to a category of damage (Table 3). For this purpose, we create a regular grid on the image and then identify the blocks and joints on the grid. More precisely, the joint coordinates are determined manually in the first step and then integrated in the grid coordinates. The local differential normal displacement of the interface between blocks is computed by the following formula:

$$
[|u|]=\boldsymbol{u}_{1} \cdot \boldsymbol{n}_{1}+\boldsymbol{u}_{2} \cdot \boldsymbol{n}_{2}
$$

Where $\mathbf{u}_{1}, \mathbf{u}_{2}$ are the normal displacements of blocks initially in "contact" along the interface and $\mathbf{n}_{1}, \mathbf{n}_{2}$ are their normal vectors respectively. A negative value of $[|\mathrm{u}|]$ corresponds to the opening of the interface between blocks

Actually, the model of structure cannot be build with perfect contact conditions between all the blocks. Small differences in sizes and slight deviations from theoretically perpendicular faces of a block lead to an initial structure were joints can be already opened. The development of the subsidence trough can lead to a partial closure of the opened joint. Furthermore, the precision of the definition of the interface depends also on the size mesh because the joints are attached on the grid. The first problem can be eliminated by taking into account the positive value of $[|\mathrm{u}|]$ in the formula (1). The second problem can be solved by taking more than two points around the interface (Fig. 2). Consequently, the joint opening width will be the maximum value of the differential displacements. This article uses a size of grid equal to $0.6 \mathrm{~mm}$ (total dimensions of wall are $238 \times 63 \mathrm{~mm}$ ) and the closest six points to the interface are chosen (Fig. 2). The vertical and horizontal joints should be separated to avoid any confusion. The next step is to classify the values of $[|\mathrm{u}|]$ in the class of damage. As the wall is represented by the discrete nodes in a regular grid, all the information are attached to these nodes. Therefore, we define the elementary discrete length in the Fig. 2. This is useful to determinate initially the total length of joints (Fig. 2a) and during the test the cumulate length of cracks for each damage class (Fig. 2b-f). As an example, for the total length of joints, the nodes of joints are assigned the number 1 , the others are 0 . The length of each node is defined in the Fig. 2a. The total length is the sum of length of nodes of joints. Identically, we compute the cumulate length of cracks for each damage class in the same way (Fig. 2b-f). Finally, the relative cumulate length is computed by the following formula:

$$
L_{\text {cum }}^{*}\left(D_{k}\right)=\frac{\Sigma l_{i}\left(D_{k}\right)}{\Sigma l_{\text {tot }}}
$$

Where $\sum_{\text {tot }}$ is the total length of joints, $\sum_{i}\left(D_{k}\right)$ is the cumulate length of cracks for the damage class $D_{k}$. 


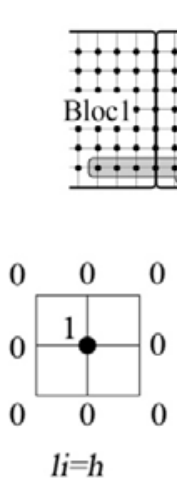

(b)

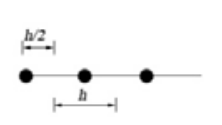

(a)

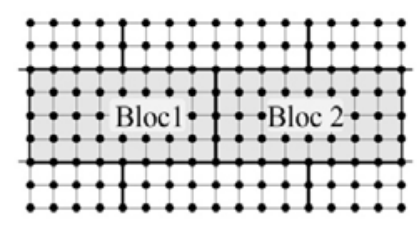

Choice of 6 points for [ $[\mathrm{u}]$

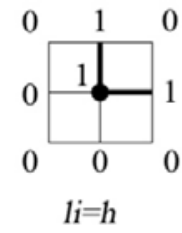

(c)

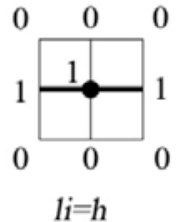

(d)

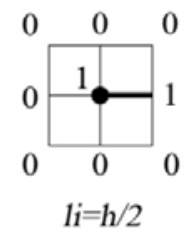

(e)

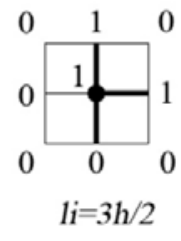

(f)

FIG. 2. Numerical schema for quantification of cracks. a) Length of points in the interface. $b \rightarrow f$ ) Length of the point (center of the rectangle) which is associated with a damage class. $h$ is the size of grid.

\section{ILLUSTRATION ON TYPICAL EXPERIMENTAL RESULTS}

The methodology is illustrated on an example of the response of the masonry structure in the tension zone of the subsidence trough (Fig. 3). During this test, a part of foundation loses contact with the soil close to the area where the subsidence is maximum (above the center of the jack). The overall behavior of the structure and its foundation is illustrated in Figure 4a through the evolution of the average slope with the displacement applied at the bottom of the tank by the electro-mechanical jack. Even though an almost linear increase of the slope is observed, the precise analysis of the deformation of the foundation shows that the relative deflexion increases linearily up to $0,64 \%$ for a jack displacement equal to $10 \mathrm{~mm}$ and then remain constant until $20 \mathrm{~mm}$ before decreasing (Fig 4b). Correspondingly, the radius of curvature decreases hyperbolically until the displacement of the jack reaches $10 \mathrm{~mm}$ (Fig 4c) and then remain stable. This can be explained by using the approximate formula of Deck and Singh 2012 to compute the value of radius of curvature (see Fig. 1).
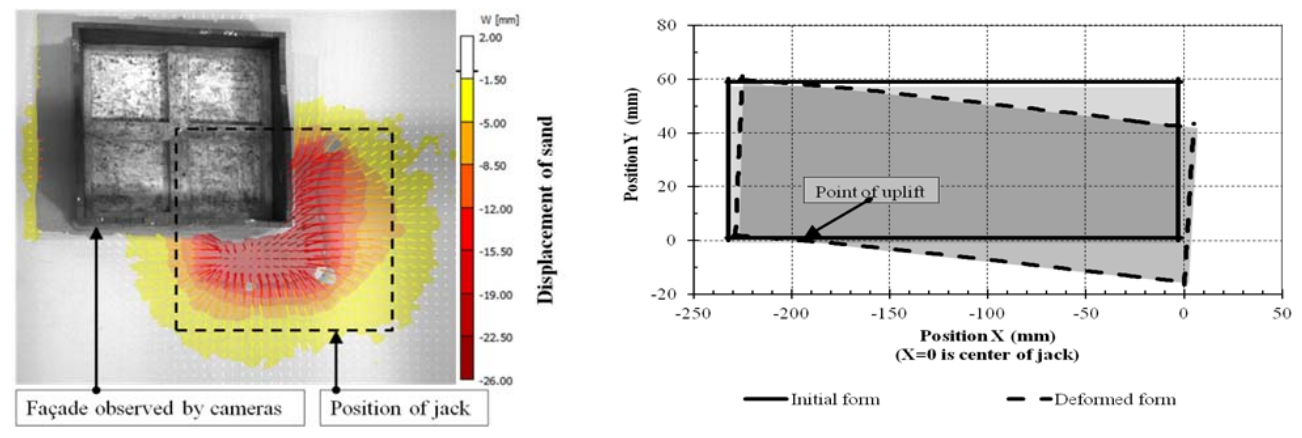

FIG. 3. Example of structure in tensile zone. 

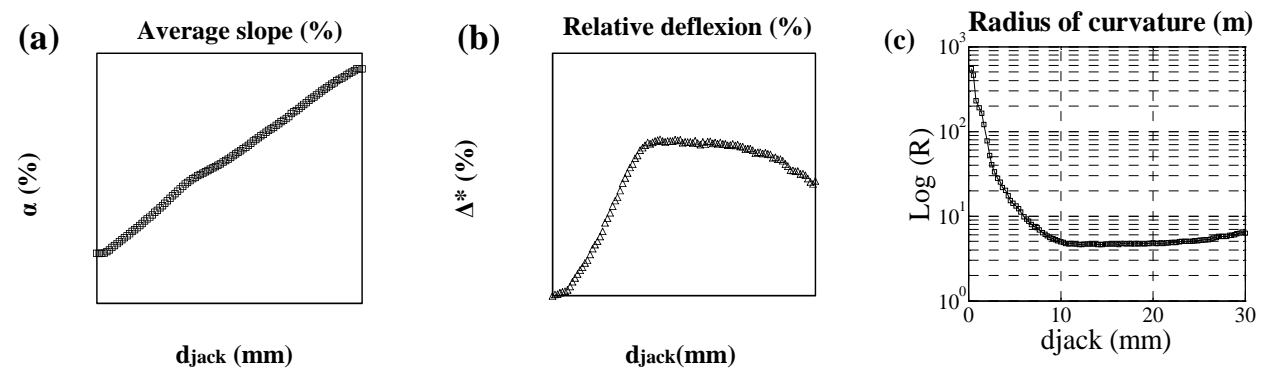
FIG 4. Evolution of average slope, relative deflection and radius of curvature
in the foundation in tensile zone.

The behavior of the wall followed by the two digital cameras is analyzed through the evolution of cumulative length of joints associated with each category of damage but also with the locations of cracks. Figure 5 shows the location of cracks: Figure 5a corresponds the fields of strain for 3 values of the displacement of the jack whereas Figure 5b illustrates the application of the algorithm for the determination of the category of damage based on the joints. The cracks propagation and development is visible in Fig. 5a: it clearly goes from a diffused distribution on the whole wall at the beginning of the test to a very localized zone at the end. This localized zone moves progressively from the right to the left with the extend of the zone of contact between the soil and the foundation. At the final state, the medium and severe cracks are distributed in the contact zone. This is coincident with the observation of Giardina et al. 2012.

The evolution of the cumulative length of joints in each damage class is shown in Fig. 6. The first two curves tend to decrease, while those of the last three categories increase with the increasing vertical displacement of the jack. Small cracks appear when the displacement of jack is small, and then they become progressively larger cracks with the increase of the displacement. 


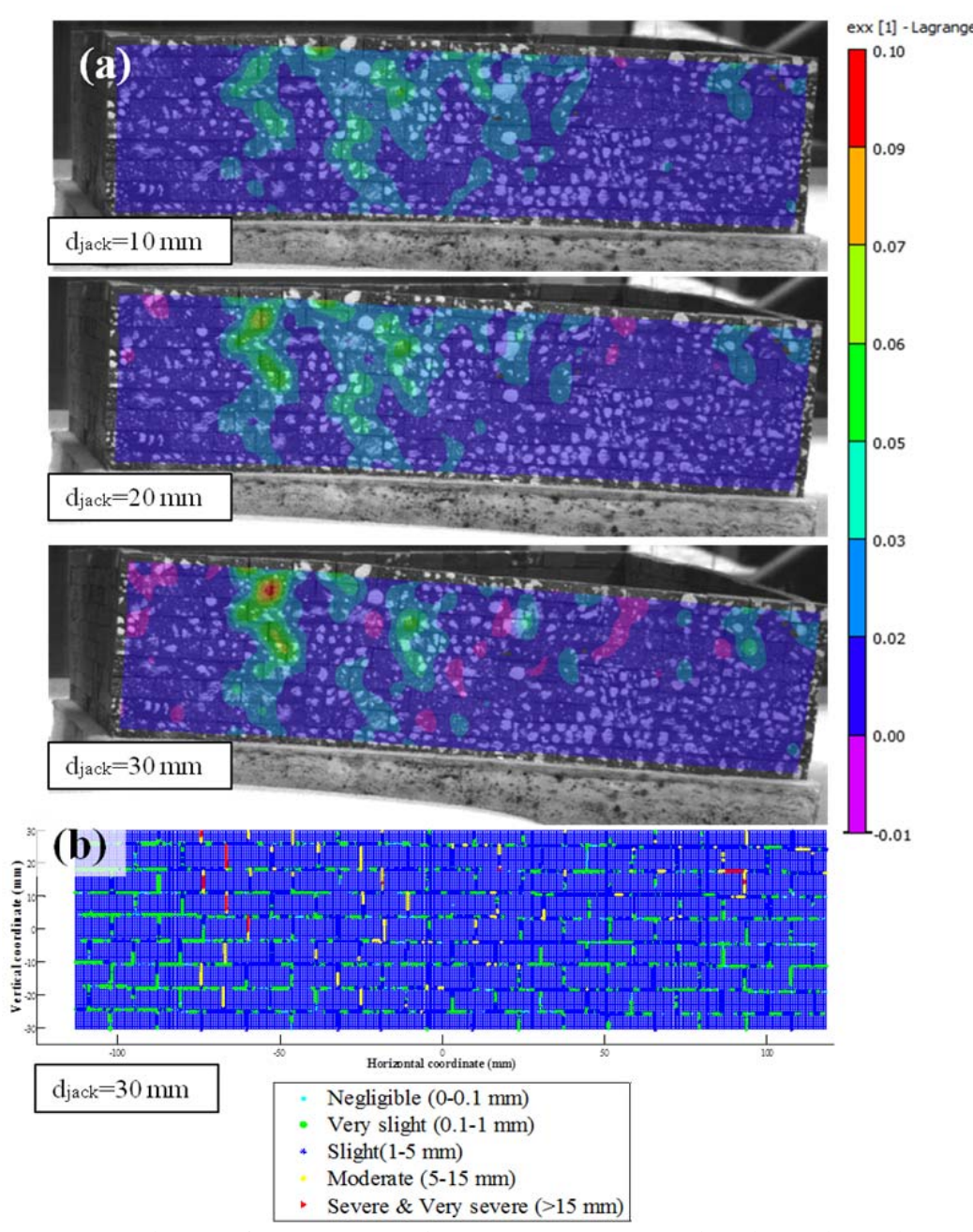

FIG. 5. Location of cracks. a) Lagrange strain in direction $x x$. b) Distribution of damage class on the façade (depending on the openings of joints).

The medium cracks $(5-15 \mathrm{~mm})$ and severe \& very severe cracks $(>15 \mathrm{~mm})$ are more relevant for the assessment of structure damage. For the medium cracks, the evolution can be divided into two parts: a linear part for $\mathrm{d}_{\text {jack }}<10 \mathrm{~mm}$ and a nonlinear part for larger displacements. When $d_{\text {jack }}=10 \mathrm{~mm}$, the cumulative relative length of the medium class is 5.54\%.

For severe \& very severe openings, the percentages of the relative cumulative length are low, less than $1 \%$. So, there is just a little variation during the descent of jack. For $d_{\text {jack }}=10 \mathrm{~mm}$, the relative cumulative length is only equal to $0.24 \%$ but this value increases slightly to $1.05 \%$ at the end of the test. 

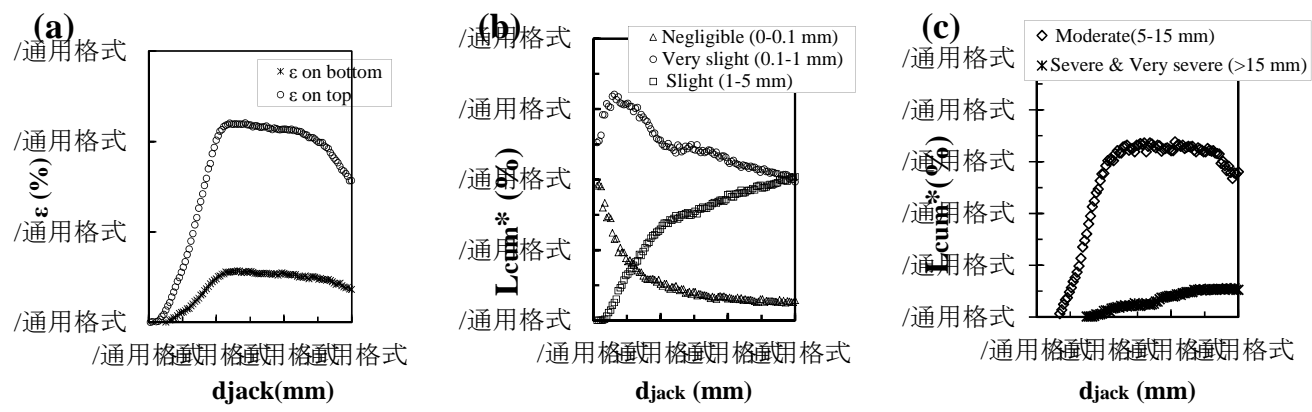

Fig. 6. Classification of damages depending on width of openings. ( $\varepsilon$ : average strain, Lcum*: relative cumulative length of opening for each damage class, djack: displacement of jack)

\section{CONCLUSIONS}

This paper has shown that the new physical model and the methods developed for the in-depth analysis of the results is a performing tool for the assessment of the vulnerability of masonry structure in subsidence zones. It appeared that the behavior of the structure in the tensile zone, the evolutions of the average slope, relative deflection, average strain, relative cumulative length of cracks can be divided into an initial linear part and a subsequent non-linear part. The relative cumulative length of cracks is considered as an accurate indicator of damage. However, for a complete evaluation of damage of the structure, it is necessary to take account to the location of cracks in addition.

Finally, this physical model can be used for the various investigations such as the influence of position of structure, the effect of openings (windows and doors) in the structure, the consideration of mortar in the masonry to more closely represent the reality.

\section{REFERENCES}

Abbass Fayad, A. (2004). "Etude de stabilité de fontis au toit des carrières souterraines et traitements apportes aux conséquences induites en surface." Ecole des Mines de Nancy, Nancy.

Al Heib, M., Nghiem, H. L., and Emeriault, F. (2013). "Understanding sinkhole consequences on masonry structures using large small-scale physical modeling." 7th international conference on Case Histories in Geotechnical Engineering The westin Chicago North Shore Wheeling Illiois.

Bazant, Z. P. (2005). Scaling of structural strength (Second edition), ButterworthHeinemann. 
Boone, S. J. (2002). "Assessing construction and settlement-induced building damage: a return to fundamental principles.", Golder Associates Inc., California, 559-570.

Boscardin, M., and Cording, E. (1989). "Building Response to Excavation-Induced Settlement." Journal of Geotechnical Engineering, 115(1), $1-21$.

Burland, J. (1997). "The assessment of the risk of damage to buildings due to tunnelling and excavations.".

Caudron, M. (2007). "Etude expérimentale et numérique de l'interaction solstructure lors de l'occurence d'un fontis." INSA de Lyon, Lyon.

Caudron, M., Hor, B., Heib, M., and Emeriault, F. (2012). "Effectiveness of a mitigation technique for buildings subjected to ground subsidence." International Journal of Geotechnical Engineering, 6(2), 179-184.

Deck, O. (2002). "Etude des conséquences des affaissements miniers sur le bâti: proposition pour une méthodologie d'évaluation de la vulnérabilité du bâti."

Deck, O., and Singh, A. (2012). "Analytical model for the prediction of building deflections induced by ground movements." International Journal for Numerical and Analytical Methods in Geomechanics, 36(1), 62-84.

Dehousse, N. M., and Arnould, R. (1971). "Les modèles réduits de structures en génie civil."Paris.

Garnier, J. "Properties of soil samples used in centrifuge models." Proc., Physical modelling in geotechnics, 5-19.

Giardina, G., Marini, A., Hendriks, M. A. N., Rots, J. G., Rizzardini, F., and Giuriani, E. (2012). "Experimental analysis of a masonry façade subject to tunnelling-induced settlement." Engineering Structures, 45(0), 421-434.

Hor, B. (2012). "Evaluation et réduction des conséquences des mouvements de terrains sur le bâti: approches expérimentale et numérique."

Hor, B., Caudron, M., Al Heib, M., and Emeriault, F. (2011). "Experimental analysis of the impact of ground movements on surface structure." 14 th PanAmerican conference on soil mechanics and geotechnical engineeringToronto, Ontario, Canada.

Potts, D. M., and Addenbrooke, T. I. (1997). "A structure's influence on tunnelling-induced ground movements." Proc. Inst. Civil Eng.-Geotech. Eng., 125(2), 109-125.

Saeidi, A., Deck, O., and Verdel, T. (2009). "Development of building vulnerability functions in subsidence regions from empirical methods." Engineering Structures, 31(10), 2275-2286. 